\section{Short Communication}

Check for updates

\section{OPEN ACCESS}

\author{
Received: Aug 11, 2018 \\ Revised: Oct 1, 2019 \\ Accepted: Oct 6, 2019 \\ Correspondence to \\ Özer Makay \\ Division of Endocrine Surgery, Department \\ of General Surgery, Ege University Hospital, \\ Kazımdirik, Universite Cd. No:9, 35100 \\ Bornova, Izmir, Turkey. \\ E-mail: ozer.makay@ege.edu.tr \\ makayozer@yahoo.com
}

Copyright (c) 2019. Korean Association of Thyroid and Endocrine Surgeons; KATES

This is an Open Access article distributed under the terms of the Creative Commons Attribution Non-Commercial License (https:// creativecommons.org/licenses/by-nc/4.0/).

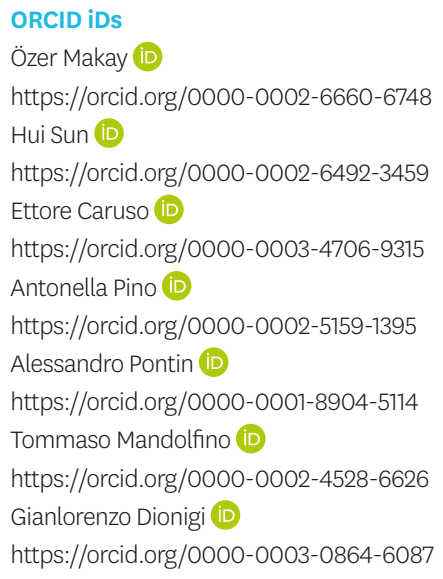
article was reported.

\title{
Preoperative Treatment with Lugol Solution for Graves' Disease
}

\author{
Özer Makay $\mathbb{D}^{1}$ ', Hui Sun $\mathbb{1}^{2}$, Ettore Caruso $\mathbb{( i b}^{3}$, Antonella Pino $\mathbb{( D}^{3}$, \\ Alessandro Pontin (1) ${ }^{3}$, Tommaso Mandolfino (1) ${ }^{4}$, Gianlorenzo Dionigi (i] ${ }^{3}$
}

'Division of Endocrine Surgery, Department of General Surgery, Ege University Hospital, Izmir, Turkey ${ }^{2}$ Division of Thyroid Surgery, Jilin Provincial Key Laboratory of Surgical Translational Medicine, China Japan Union Hospital of Jilin University, Changchun, China

${ }^{3}$ Division for Endocrine and Minimally Invasive Surgery, Department of Human Pathology in Adulthood and Childhood “G. Barresi”, University Hospital G. Martino, University of Messina, Messina, Italy ${ }^{4}$ Department of Human Pathology in Adulthood and Childhood "G. Barresi”, University Hospital G. Martino, University of Messina, Messina, Italy

\section{ABSTRACT}

Graves' disease is one of the commonest causes of hyperthyroidism. Pre-treatment with Lugol solution, containing iodine/potassium iodide, to induce euthyroidism before surgery may be suggested, especially in case of adverse events due to antithyroid medication. Whether post-operative outcomes are any different following a course of Lugol solution in patient with Graves' disease is not well-documented in the literature. It is definite that large, prospective, randomized controlled trials of clinical and scientific are warranted to answer whether or not preparation with Lugol solution is necessary prior to surgery for Graves' disease.

Keywords: Graves's disease; Thyroidectomy; Lugol solution

Total thyroidectomy is the preferred operative approach for Graves' disease (GD). Guidelines of the American Thyroid Association (ATA) suggest the administration of potassium iodide and achievement of euthyroid state before operation $(1,2)$. Preoperative treatment with lugol solution (LS) - introduced in the 1920s-led to a decline in endocrine operative mortality. In Europe, in many hospitals up to the 1980s and 1990s, GD was pre-treated with LS as standard of care $(1,2)$. As a surgical advantage, the significantly reduced blood flow of the hypervascularized thyroid gland was observed after several days of LS administration $(1,2)$. Today, following the establishment of beta-blockers and antithyrotoxic agents, pretreatment with LS is usually limited to exceptional situations. However, it is recommended as a routine procedure by ATA in its guidelines (“...Whenever possible, patients undergoing thyroidectomy should be euthyroid with methimazole, and pancreatic potassium iodide should be given in the preoperative period...") (1). Whether preoperative pretreatment of GD with LS is actually advantageous from a surgical point of view should be clarified by a systematic literature analysis.

On the basis of Ovid Medline, PubMed and the ATA website, 194 English-language papers on the subject of preoperative treatment with LS were identified in the management of GD (2). Four papers, published between 2007 and 2014, were considered suitable for analysis and grouped according to their evidence (2,3). One paper (A: Erbil et al., (4)) had evidence level 1, 


\section{Author Contributions}

Conceptualization: Özer Makay, Hui Sun, Ettore Caruso, Antonella Pino, Alessandro Pontin, Tommaso Mandolfino, Gianlorenzo Dionigi; Writing - original draft: Özer Makay, Hui Sun, Ettore Caruso, Antonella Pino, Alessandro Pontin, Tommaso Mandolfino, Gianlorenzo Dionigi; Writing - review \& editing: Özer Makay, Hui Sun, Ettore Caruso, Antonella Pino, Alessandro Pontin, Tommaso Mandolfino, Gianlorenzo Dionigi. and the other 3 papers were classified as level 2 (B: Yabuta et al., (5); C: Shinall et al., (6); D: Santosh et al. (7)).

In detail, the mentioned works showed the following results (4-7):

A: Vascularization and intraoperative blood loss were significantly reduced after LS administration.

B: No difference of intraoperative blood loss between patients with or without pretreatment with LS.

C: No difference of intraoperative blood loss in patients with hyperthyroidism due to autonomic nodular goiter or GD, with or without pre-treatment by LS.

D: No difference in the postoperative complication rates in patients with or without LS.

The present systematic literature analysis does not provide sufficient evidence for an advantage of the routine preoperative administration of LS in GD (2). Neither the intraoperative blood loss, nor the postoperative complication rates differed significantly from those with beta-blockers and/or pretreated patients (2). The recommendation on LS pre-treatment given in the ATA guidelines therefore lacks its evidence-based basis (1). The authors' recommendation for carrying out a prospective randomized study will certainly only be accepted where the preoperative administration of LS is still a practical routine in the surgical treatment of GD $(2,3,8)$.

\section{REFERENCES}

1. Bahn RS, Burch HB, Cooper DS, Garber JR, Greenlee MC, Klein I, et al. Hyperthyroidism and other causes of thyrotoxicosis: management guidelines of the American Thyroid Association and American Association of Clinical Endocrinologists. Endocr Pract 2011;17:456-520. PUBMED | CROSSREF

2. Hope N, Kelly A. Pre-operative Lugol's iodine treatment in the management of patients undergoing thyroidectomy for Graves' disease: a review of the literature. Eur Thyroid J 2017;6:20-5. PUBMED | CROSSREF

3. Dralle H. Lugol's solution for preoperative pretreatment in Grave's disease. Chirurg 2017;88:446. PUBMED | CROSSREF

4. Erbil Y, Ozluk Y, Giriş M, Salmaslioglu A, Issever H, Barbaros U, et al. Effect of lugol solution on thyroid gland blood flow and microvessel density in the patients with Graves' disease. J Clin Endocrinol Metab 2007;92:2182-9. PUBMED | CROSSREF

5. Yabuta T, Ito Y, Hirokawa M, Fukushima M, Inoue H, Tomoda C, et al. Preoperative administration of excess iodide increases thyroid volume of patients with Graves' disease. Endocr J 2009;56:371-5. PUBMED | CROSSREF

6. Shinall MC Jr, Broome JT, Baker A, Solorzano CC. Is potassium iodide solution necessary before total thyroidectomy for Graves disease? Ann Surg Oncol 2013;20:2964-7. PUBMED | CROSSREF

7. U P S, K B P, Karanam L. Preoperative preparation with Lugol's iodine in thyroidectomy of euthyroid patients-is it really mandatory?-An otorhinolaryngologist's view. J Clin Diagn Res 2014;8:KC01-2. PUBMED | CROSSREF

8. Shinall MC Jr, Broome JT, Nookala R, Shinall JB, Kiernan C, Parks L 3rd, et al. Total thyroidectomy for Graves' disease: compliance with American Thyroid Association guidelines may not always be necessary. Surgery 2013;154:1009-15. PUBMED | CROSSREF 